\title{
PROMOSI KESEHATAN PENCEGAHAN DAN PENANGGULANGAN PENYAKIT HIV/AIDS DI KARANG TARUNA X DAN Y CINERE, DEPOK
}

\author{
Ria Maria Theresa ${ }^{1}$, Nunuk Nugrohowati ${ }^{2}$ dan Andri Pramesyanti ${ }^{3}$ \\ ${ }^{1}$ Departemen Kesehatan Jiwa, FK UPN Veteran Jakarta \\ Email: ibunda.ria@gmail.com \\ ${ }^{2}$ Departemen Kesehatan Masyarakat, FK UPN Veteran Jakarta \\ Email: nnugrohowati@gmail.com \\ ${ }^{3}$ Departemen Mikrobiologi, FK UPN Veteran Jakarta \\ Email: andripramesyanti@gmail.com
}

\begin{abstract}
ABSTRAK
Latar Belakang:Pergaulan kelompok remaja sampai dewasa yang ada di kecamatan Cinere Kota Depok pada kelompok umur produktif aktif secara seksual menurut masyarakat umum sudah mengarah pada pergaulan yang aneh, berupa maraknya perilaku LGBT (Lesbian, Gay, Biseksual, Transgender). Menurut Radar Depok, Direktur Program NGO Kuldesak mengatakan peningkatan penderita ODHA di Depok adalah $10 \%$ yang disumbangkan dari perilaku LGBT. Laporan Profil Dinas Kesehatan Kota Depok 2017 bahwa jumlah kasus HIV di Kota Depok tahun 2014 ada 49 kasus, tahun 2015 sebanyak 146 kasus, tahun 2016 ada 278 kasus, tahun 2017 kasus HIV meningkat menjadi 372 kasus. Tujuan: Kendala dalam memberikan pengarahan kepada masyarakat, cara pencegahan pada kelompok umur produktif tersebut agar melaksanakan kehidupan dengan perilaku dan gaya hidup yang baik, mendorong kami melaksanakan pengabdian pada masyarakat di daerah Cinere. Metode: Mitra I anggota kader pendamping ODHA di Cinere membantu melaksanakan Promosi kesehatan Pencegahan dan Penanggulangan Masyarakat Penyakit HIV-AIDS dengan harapan para kader dapat menemukan penderita HIV secara volunteer dan melalui survei pada saat dilakukan promosi kesehatan. Mitra II kelompok Karang Taruna kecamatan Cinere dengan anggota usia antara 19-45 tahun berjumlah 50 orang. Hasil dan Kesimpulan: Sebagai pencegahan terhadap penularan penyakit HIVAIDS serta menjaring ODHA yang masih belum diobati setelah dilakukan penyuluhan, disarankan dibentuk Kelompok Teman Sebaya pada karang taruna untuk ikut menginformasikan kepada teman di lingkungan tentang perilaku seks kurang sehat yang dapat menimbulkan penyakit.
\end{abstract}

Kata Kunci: Cara pencegahan; Pendamping ODHA; Perilaku dan gaya hidup; Umur produktif.

\section{PENDAHULUAN}

\section{Analisis Situasi}

Lokasi Mitra I dan II adalah daerah Kelurahan Gandul Kecamatan Cinere Kota Depok. Kecamatan Cinere adalah daerah yang mengalami perubahan cepat dalam perkembangan sosial budaya, kehidupan bermasyarakat dan beragama sebagai akibat dari perubahan pola penduduk dari desa btradisional menjadi kota moderen. Pergaulan antar remaja sampai dewasa pada kelompok umur produktif yang aktif secara seksual di daerah ini menurut masyarakat umum sudah mengarah pada penyimpangan perilaku diluar normal/LGBT.

Menurut laporan Koran Depok yang bernama Radar Depok, Walikota Depok, Mohammad Idris mengeluarkan instruksi Walikota Depok Nomor 2 Tahun 2018 tentang Pelaksanaan Penguatan Ketahanan Keluarga terhadap Perilaku Menyimpang Seksual. Instruksi ini terkait menjamurnya perilaku lesbian, gay, biseksual, transgender (LGBT) di Kota Depok. Disamping itu dikeluarkan juga Surat Edaran Nomor 460/90-Dinsos tentang Pelaksanaan Penguatan Ketahanan Keluarga terhadap Perilaku Penyimpangan Seksual. Walikota mengajak seluruh elemen terkait di wilayah ini 
untuk menjaga dan memelihara masyarakat dari dampak yang ditimbulkan oleh perilaku kelompok menyimpang agar tidak meluas dan dapat ditanggulangi bersama, melaporkan aktivitas perilaku LGBT di lingkungan sekitarnya dan menjaga lingkungan masing-masing agar terhindar dari perilaku menyimpang seksual.

Permasalahan yang dihadapi oleh mitra I adalah bagaimana melakukan pendekatan kepada kelompok rentan (mitra II) sehingga dari lingkungan mereka kita dapat mendeteksi awal gejala yang sedang terjadi pada lingkungan kelompok rentan. Untuk menjangkau dan menjaring orang dengan gejala ODHA maka kita harus menggunakan lingkungan mereka sendiri untuk melakukan pendekatan. Kurangnya pengetahuan atau pengetahuan yang didapat dari sumber informasi yang tidak tepat sangat berbahaya karena dapat menjerumuskan lingkungan yang mempunyai indikasi lingkungan social budaya yang rentan.

\section{Permasalahan Mitra I dan II}

a. Perlunya dukungan untuk pendamping ODHA dalam memberikan pengetahuan kepada masyarakat kelompok rentan tentang bahayanya perilaku LGBT yang dapat menyebabkan timbul dan menularnya penyakit HIV AIDs. Perilaku LGBT sangat bertentangan dalam segi sosial budaya, agama dan mengganggu kehidupan masyarakat umum.

b. Dukungan tersebut berupa pemberian materi promosi kesehatan tentang HIV AIDS kepada kelompok rentan dalam usia aktif dalam masalah seksual dalam hal ini adalah kelompok Karang Taruna di kelurahan Gandul Kecamatan Cinere Kota Depok. Prioritasnya adalah menganjurkan adanya kelompok Teman Sebaya dalam Karang Taruna. Hasil pelaporan dari teman sebaya tersebut kemudian dievaluasi dan di tindak lanjuti.

\section{METODE PELAKSANAAN PKM}

Metode pelaksanaan kegiatan dalam melaksanakan solusi yang ditawarkan untuk mengatasi permasalahan yang ada:

1. Sebagai upaya mencegah terjadinya perilaku menyimpang di kalangan kelompok rentan adalah mencari solusi dari permasalahan mitra, yaitu: Pelaksanaan Program Kemitraan Masyarakat berupa promosi kesehatan tentang HIV AIDS kepada kelompok rentan dalam usia aktif dalam masalah seksual dalam hal ini adalah kelompok Karang Taruna di kelurahan Gandul Kecamatan Cinere Kota Depok

2. Promosi kesehatan dilakukan dengan partisipasi dan kerja sama dengan para pendamping ODHA sebagai mitra I di kecamatan Cinere, dilakukan di Aula Gedung pertemuan dengan dihadiri para pemuda yang tergabung dalam Kelompok Karang Taruna sebagai mitra II di kelurahan Gandul Kecamatan Cinere.

3. Metode pendekatan yang ditawarkan untuk menyelesaikan persoalan mitra setelah mengambil kesepakatan bersama dengan Mitra I adalah membuat kelompok teman sebaya dalam karang taruna tersebut. Ditentukan key person/anak muda yang menjadi panutan/dipercaya oleh kelompok tersebut, diharapkan dia dapat memimpin untuk menyebarkan pengetahuan dan contoh pergaulan yang baik dan positif, memberi nasehat sebagai bentuk pencegahan terhadap perilaku yang menyimpang, mencatat informasi 
terhadap pemuda yang sudah mempunyai gejala perilaku yang menyimpang untuk segera mendapat pertolongan.

4. Langkah evaluasi pelaksanaan program adalah pelaporan hasil yang sudah dilakukan oleh kelompok teman sebaya, dan tindakan yang akan dilakukan setelah melihat hasil evaluasi tersebut.

Diharapkan program kelompok teman sebaya akan terus berlanjut di lapangan walaupun kegiatan PKM selesai dilaksanakan. Peran pendamping ODHA perlu mendapat dukungan dari pemerintah daerah setempat untuk kelangsungan program ini, demi mendapatkan hasil positif dan efektif dalam rangka pencegahan menularnya penyakit HIV AIDS.

Materi penyuluhan :

1. Pendidikan mengenai HIV/AIDS

2. Program Pencegahan tentang HIV / AIDS dan penyuluhan terkait Perilaku Menyimpang

3. PenentuanTeman Sebaya

Media yang akan digunakan adalah:

1. Pengisian kuesioner

2. Presentasi materi dalam bentuk power point dengan menggunakan peralatan laptop dan infokus. Materi dalam bentuk power point.

3. FGD (Focus Grup Discussion).

\section{HASIL DAN PEMBAHASAN}

Selama pelaksanaan animo peserta sangat baik dan interaktif dalam menerima materi Edukasi mengenai Pencegahan dan Penanggulangan HIV/AIDS. Hal ini dibuktikan dengan antusiasme peserta yang hadir untuk memperhatikan dan selama pelaksanaan kegiatan tersebut,

Kegiatan pertama adalah Promosi kesehatan dilakukan oleh narasumber dengan partisipasi dan kerjasama dari para pendamping ODHA sebagai mitra I kepada Kelompok Karang Taruna sebagai mitra II di kelurahan Gandul Kecamatan Cinere.

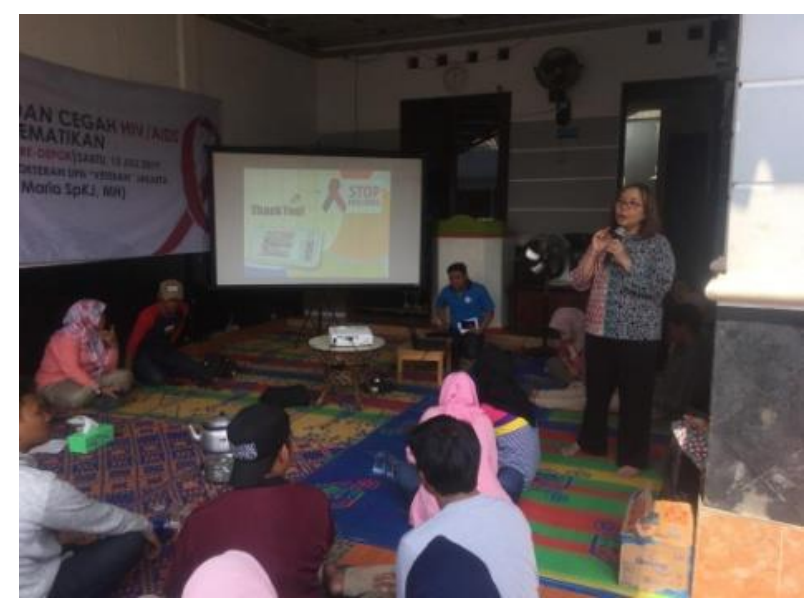

Gambar 1. Kegiatan Penyuluhan 
Kehadiran peserta laki dan perempuan berjumlah 50 orang. Pelaksanaan kegiatan pengabdian sesuai dengan waktu yang dijadwalkan, Penyampaian materi sesuai rencana.

Sebelum diberikan penyuluhan, para remaja, kader dan peserta lain diberikan kuesioner untuk menilai sejauh mana tingkat pengetahuan para peserta mengenai penyakit HIV/AIDS, sikap dan perilaku terhadap penyakit HIV/AIDS, pencegahan serta penanggulangan HIV/AIDS. Indikator yang digunakan adalah: Usia, Jenis Kelamin, dan Jenis Kegiatan para responden

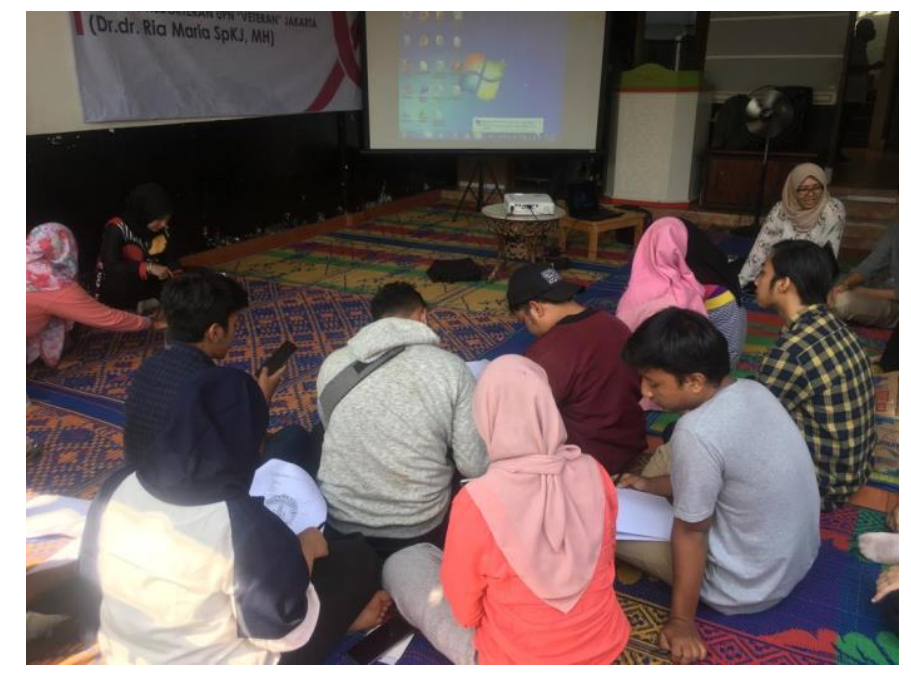

Gambar 2. Kegiatan Pengisian kuesioner oleh para responden

Berdasarkan data yang terkumpul dilakukan pembahasan, dengan hasil sebagai berikut:

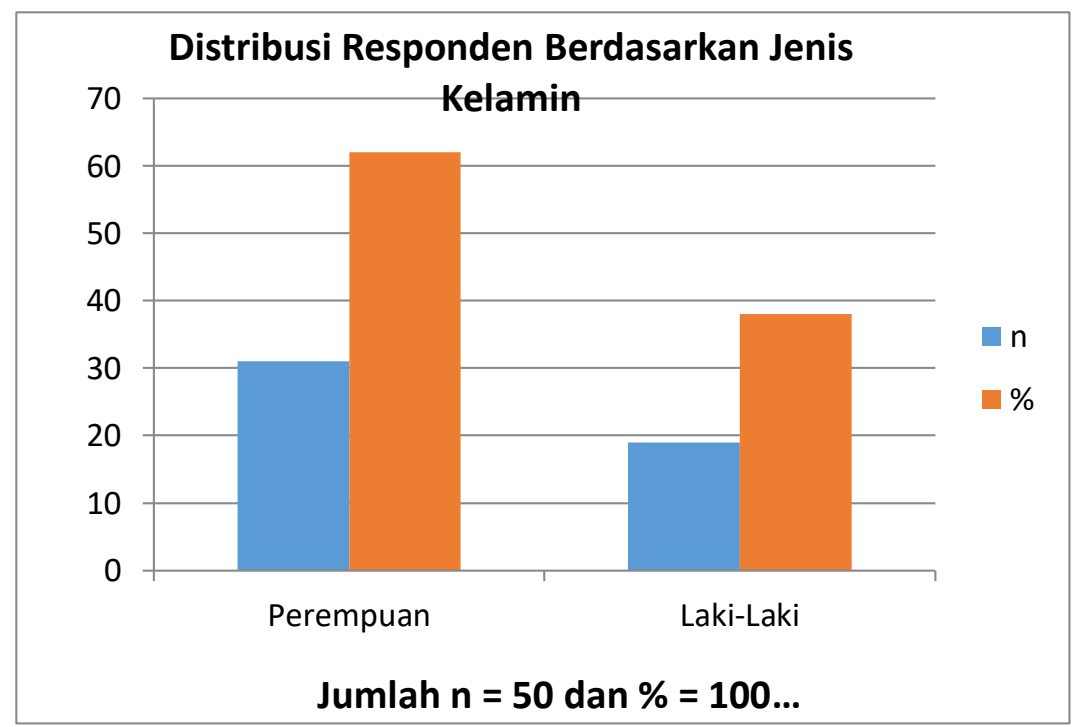

Gambar 3. Distribusi Responden Berdasar Jenis Kelamin 


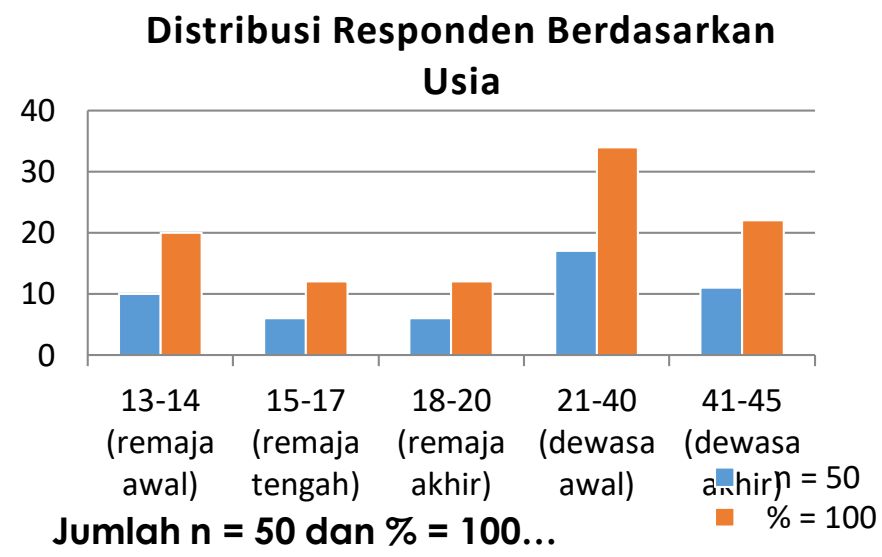

Gambar 4. Distribusi Responden berdasar Usia

\section{Distribusi Responden berdasar jenis kegiatan/pekerjaan}

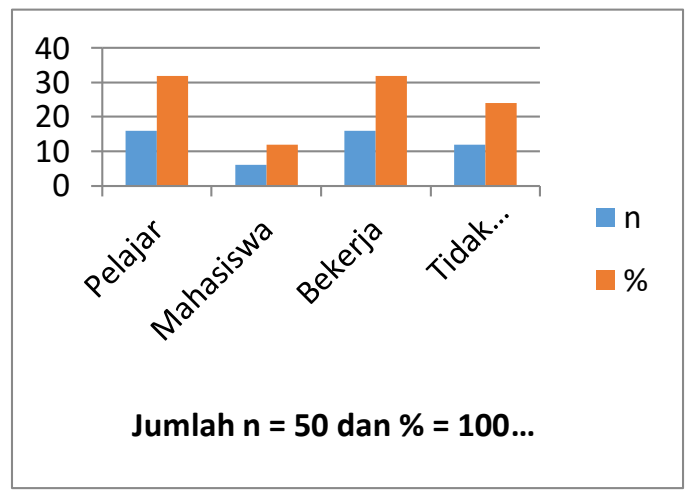

Gambar 5. Distribusi Responden berdasar jenis kegiatan/pekerjaan

Tabel 1. Distribusi Responden Berdasar Pengetahuan

\begin{tabular}{ccc}
\hline Pengetahuan & n & \% \\
\hline Kurang & 16 & 32.0 \\
Sedang & 13 & 26.0 \\
Baik & 21 & 42.0 \\
\hline Jumlah & 50 & 100 \\
\hline \multicolumn{3}{l}{ Sumber: Data Primer, 2019 }
\end{tabular}

Tabel 2. Distribusi Responden Berdasar Sikap

\begin{tabular}{lcc}
\hline \multicolumn{1}{c}{ Sikap } & n & \% \\
\hline Negatif & 24 & 48 \\
Positif & 26 & 52 \\
\hline Jumlah & 50 & 100 \\
\hline \multicolumn{2}{c}{ Sumber: Data Primer, 2019 }
\end{tabular}


Tabel 3: Distribusi Responden Berdasar Kecenderungan Perilaku Menyimpang Kearah Perilaku LGBT

\begin{tabular}{ccc}
\hline $\begin{array}{c}\text { Kecenderungan } \\
\text { Perilaku LGBT }\end{array}$ & n & \% \\
\hline Positif & 22 & 44 \\
Negatif & 28 & 56 \\
\hline Jumlah & 50 & 100 \\
\hline \multicolumn{2}{c}{ Sumber: Data Primer, 2019}
\end{tabular}

Penyuluhan mengenai Pencegahan dan Penanggulangan HIV/AIDS ini diikuti oleh 50 orang anggota Karang Taruna X dan Y yang didominasi oleh anggota wanita (Gambar 3). Ada kemungkinan anggota laki-laki malu untuk hadir di acara seperti ini. Acara ini juga paling banyak dihadiri oleh anggota yang berusia antara 21-40 tahun, alasan yang paling bisa diterima adalah pada usia ini mereka mempunyai keingin tahuan yang besar tentang suatu hal dan mulai terbuka untuk menerima informasi. Acara ini juga paling banyak dihadiri oleh anggota yang berprofesi sebagai pelajar dan yang sudah bekerja.Informasi yang menarik dan bermanfaat menjadi perhatian mereka untuk hadir pada acara ini. Pada Tabel 1 terlihat Pengetahuan baik adalah paling tinggi sehingga dikatakan bahwa pada Karang Taruna X dan Y masih banyak yang mempunyai pengetahuan yang baik tentang penyakit HIV/AIDs. Sikap positif juga masih ditunjukkan oleh anggota Karang Taruna X dan Y (Tabel 2) sehingga diharapkan penyuluhan ini memberikan sikap yang baik pada diri mereka. Pada tabel 3 kecenderungan perilaku LGBT lebih banyak segi negatifnya, ini berarti sebagian besar anggota Karang Taruna masih menganggap kecenderungan perilaku LGBT adalah perilaku negatif.

Setelah pelaksanaan penyuluhan dan pemberian materi dilakukan Focus Grup Discussion ( $F G D$ ) di antara peserta, saling berbagi pengalaman dan kemungkinan membentuk grup teman sebaya. Mereka menyatakan informasi tentang HIV / AIDS sudah bisa disebarkan oleh keluarga dan tetangga, sehingga teman sebaya menjadi prioritas berikutnya setelah keluarga dan tetangga. Dalam kegiatan FGD ini ada beberapa pertanyaan dari remaja dan kader yang langsung dijawab oleh narasumber.

\section{KESIMPULAN}

Kegiatan IPTEK bagi Masyarakat berbasis promosi kesehatan mengenai pencegahan dan penanggulangan mengenai HIV/AIDS berupa penyuluhan diterima dengan baik oleh Mitra 1 kelompok rentan dalam usia aktif dalam masalah seksual dan kader sebagai mitra 2, Peserta memperoleh pengetahuan melalui penyuluhan mengenai HIV/AIDS sebagai upaya pencegahan serta penurunan prevalensi di Indonesia dan Kota Depok secara khusus,

Diharapkan hasil kegiatan pengabdian kepada masyarakat ini dapat memberikan informasi mengenai pencegahan dan penanggulangan penyakit HIV/AIDS secara menyeluruh serta dapat diterapkan dalam kehidupan sehari-hari. 


\section{REFERENSI}

1. Alan, L, Miller, ND 2005, „Epidemiology, Etiology, and Natural Treatment Of Seasonal Affective Disorder ${ }^{\mathrm{e}}$, Alternative medicine review, vol. 10, hlm.2, diakses 22 April 2017, <http://www.thorne.org/altmedrev/.fulltext/10/1/5.pdf>

2. Budiman, A 2015, Penggunaan Narkoba \& HIV, Yayasan spiritia, diakses 22 April 2017, http://spiritia.or.id/li/bacali.php?lino=154

3. Ditjen PP \& PL Kementerian Kesehatan RI 2011, Laporan Perkembangan Situasi HIV \& AIDS Di Indonesia Triwulan 2 Tahun 2011, diakses 20 Mei 2017, http://www.aidsindonesia.or.id/ck_uploads/files/Final\%20Laporan\%20HIV\% 20AIDS\%20TW\%201\%202016.pdf

4. Intermedika 2017, ODHA pada Gay, Yayasan Intermedika Jakarta, diakses 24 Januari 2018, http://www.intermedika.org/category/komunitas/yimoet/

5. Komisi penanggulangan AIDS 2010-2011, Pengertian dan Pencegahan HIV/AIDS,

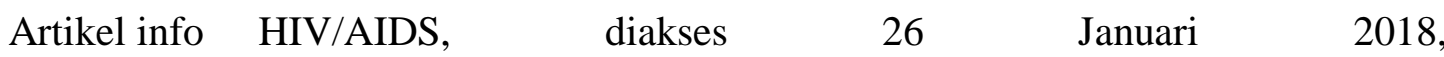
http://www.aidsindonesia.or.id/dasar-hiv-aids

6. Radar Depok, Koran Depok sesungguhnya, 2018

7. Laporan Kesehatan Kota Depok, 2016

8. Notoatmojo, S 2012, Metodologi Penelitian Kesehatan, Edisi Revisi cetakan kedua, Rineka Cipta, Jakarta

9. Suprajitno 2004, Asuhan Keperawatan Keluarga 1st edn, Jakata, Penerbit Buku Kedokteran EGC

10. Widayati 2016, „Identification Of Psychological Status As An Effort To Develop Community- Based Hiv/Aids Client Rehabilitation Model ${ }^{e e}$, Nurseline Journal, vol.1, diakses 1 Juni 2017, https://jurnal.unej.ac.id/index.php/NLJ/article/view/3834 